Article

\title{
Arsenic Exposure and Methylation Efficiency in Relation to Oxidative Stress in Semiconductor Workers
}

\author{
Chih-Hong Pan ${ }^{1,2, *}$, Ching-Yu Lin ${ }^{3,4} \mathbb{D}$, Ching-Huang Lai ${ }^{2}$ and Hueiwang Anna Jeng 5 \\ 1 Institute of Labor, Occupational Safety and Health, Ministry of Labor, New Taipei City 22143, Taiwan \\ 2 School of Public Health, National Defense Medical Center, Taipei 11490, Taiwan; lgh@ndmctsgh.edu.tw \\ 3 School of Medical Laboratory Science and Biotechnology, College of Medical Science and Technology, \\ Taipei Medical University, Taipei 11031, Taiwan; cylin@tmu.edu.tw \\ 4 College of Medical Science and Technology, Taipei Medical University, Taipei 11031, Taiwan \\ 5 School of Community and Environmental Health, College of Health Sciences, Old Dominion University, \\ Virginia, VA 23529, USA; HJeng@odu.edu \\ * Correspondence: chpan@mail.ilosh.gov.tw
}

Received: 19 March 2020; Accepted: 1 May 2020; Published: 4 May 2020

\begin{abstract}
This study examined associations between oxidative stress and arsenic (As) exposure and methylation efficiency in semiconductor workers. An As-exposed group $(n=427)$ and a control group $(n=91)$ were included. The As-exposure group $(n=427)$ included 149 maintenance staff members and 278 production staff members representing high As exposure and low As exposure, respectively. The control group included 91 administrative staff members with no or minimal As exposure. An occupational exposure assessment was conducted to assess personal As exposure by measuring As concentrations in urine, hair, and fingernails of the subjects. Urinary $\mathrm{As}(\mathrm{III}), \mathrm{As}(\mathrm{V})$, monomethylarsonic (MMA), and dimethylarsinic acid (DMA) were quantified to assess an internal dose of inorganic As. Urinary 8-hydroxy-2'-deoxyguanosine (8-OHdG) and malondialdehyde (MDA) were measured to asses oxidative DNA damage and lipid peroxidation, respectively. As concentrations in urine, hair, and fingernails significantly increased $(p<0.05)$ in the As-exposed group in comparison to the control group. Geometric mean urinary concentrations of As, 8-OHdG, and MDA in the As-exposed group significantly exceeded those in the control group. As exposure to As-exposed workers had increased concentrations of 8-OHdG in contrast to those in control subjects. Moreover, urinary 8-OHdG concentrations in the semiconductor workers were positively correlated with urinary total As metabolite $(\mathrm{As}(\mathrm{III})+\mathrm{As}(\mathrm{V})+\mathrm{MMA}+\mathrm{DMA})$ concentrations. Furthermore, urinary excretion of 8-OHdG concentrations in As-exposed workers were positively associated with urinary excretion of MMA concentrations and primary methylation index values (the ration of MMA/inorganic As). However, fingernail and hair samples did not perform as well as urinary samples to measure oxidative stress induced by As exposure. 8-OHdG could serve as a more reliable biomarker for assessing As methylation than MDA did. Occupational exposure to inorganic As was associated with increased oxidative stress among semiconductor workers.
\end{abstract}

Keywords: arsenic; inorganic arsenic metabolites; methylation efficiency; semiconductor workers; oxidative stress

\section{Introduction}

Inorganic arsenic (As) is extensively used in the semiconductor manufacturing process, particularly during ion implantation to impart conductivity to the wafer [1,2]. Each step of wafer fabrication involves a cleaning process. Due to the nature of the process, semiconductor workers risk exposure to 
inorganic As in indoor air. Exposure routes include inhalation of airborne particulate matter and toxic gas released during maintenance and cleaning activities [3]. Occupational exposure assessment studies reported that preventive maintenance engineers who regularly handle clean equipment and disposing of As wastes are exposed to higher As concentration as compared to other groups of semiconductor workers, e.g., operators.

Upon entering the biological system, inorganic As is easily absorbed into the blood, where pentavalent arsenic $(\mathrm{As}(\mathrm{V}))$ involves a two-electron reduction and forms trivalent arsenic (As(III)). As(III) then undergoes a series of oxidative methylation and reduction to form monomethylarsonic acid $(\mathrm{MMA}(\mathrm{V}))$ and dimethylarsinic acid $(\mathrm{DMA}(\mathrm{V}))$ primarily in the liver. Inorganic As has been recognized as the primary species contributing to As toxicity. Originally, the methylation process was considered a detoxification process to form As metabolites that are readily excreted in urine. However, recent studies have found some active, methylated As metabolites can produce toxicity [4,5]. For example, MMA and DMA are funded to be linked to increased risk of cancer [6-8]. Considering the toxicity of methylated As metabolites, As methylation efficiency in humans has been considered in health risk assessment of As toxicity and associated health impact. The primary methylation index (PMI) and secondary methylation index (SMI), a ratio of MMA to inorganic As and a ratio of DMA to MMA, have been used to represent the As methylation efficiency [9]. Epidemiological studies have shown that poor methylation efficiency, represented high PMI and low SMI, is associated with increased risk of developing As-induced diseases [10,11].

Both inorganic and organic As can be excreted from the body in urine. As(III) and As(V) make up $10 \%-20 \%$ of the total As concertation in urine, while MMA and DMA contribute to $10 \%-15 \%$ and $60 \%-80 \%$, respectively [12]. Since the majority of As is absorbed from the lungs and/or the gastrointestinal track and eventually excreted in the urine, measurement of urinary As metabolites can serve as a reliable biomarker for recent exposure to As. Such measurement is correlated with exposure of inhaled inorganic As to workers involved with an As industrial process and the populations living near industrial point source of As [13]. Measurement of bioaccumulated As concentrations in hair and fingernails has been considered as an effective marker for chronic exposure to As in the human body $[2,14]$, since fingernails grow slowly and can affect the health status of cells on the fingernails' root [14].

Increasing evidence suggests that exposure to As contributes to increased risk of a wide range of negative health effects. Acute As could affect organic systems, e.g., the dermal, hematopoietic, gastrointestinal, reproductive, and cardiovascular systems. Long-term exposure to As has been linked to peripheral neuropathy, cardiac and peripheral vascular disease, anemia, hyperkeratosis, and hyperpigmentation of the skin $[15,16]$. Epidemiological studies have suggested that exposure to inorganic As links to increased risk of cancer of the skin, liver, bladder, and lung [15,16]. Both in vitro and in vivo studies have suggested that inorganic As increase genotoxicity. For example, occupational exposure to As among workers in a glass plant experienced urinary As five times higher than in the control group. These workers reported to have increased 8-hydroxy-2'-deoxyguanosine (8-OHdG) in leukocytes. 8-OHdG is one of the major products of DNA oxidation, which originates from the reaction of hydroxyl radicals with guanosine at the C-8 position in DNA.

Mechanistic studies of As toxicity have suggested that reactive oxygen species (ROS)-mediated oxidative damage is involved with As pathogenesis. Metabolism of inorganic As in living cells can increase the generation of ROS, including superoxide, hydroxyl radical, and peroxyl radicals. Mechanistic pathways showed that the oxidation of As(III) to As(V) form intermediary As species, e.g., dimethylarsinic peroxyl ((CH3)2AsOO.) and dimethylarsinic radicals ((CH3)2As•) involving (O2•-). Subsequently, ROS species were formed during the reactions. In addition, inorganic As metabolism can be involved with lipid peroxidation and forms byproducts, e.g., malondialdehyde (MDA) and 4-hydroxy-nonenal (HNE) [17,18]. MDA is one of the stable aldehydic products of lipid peroxidation that are present in biological samples such as urine, hair, or blood. It can serve as a biomarker reflecting the global oxidative status of the human body [19-22]. 
Increasing studies have been conducted to examine associations between As exposure and health outcomes of workers in the semiconductor manufacturing industries. However, a few studies have examined relations between As exposure using speciated As metabolites in semiconductor workers and occupational factors. In addition, these studies only measured urinary As to recent exposure in semiconductor workers without well-defined occupational classification $[6,23,24]$. Furthermore, those studies did not examine associations between speciated As metabolites from chronic exposure and As exposure-mediated oxidative effects in semiconductor workers. Finally, few studies have been conducted to assess oxidative stress effects for both short- and long-term exposure to As in semiconductor workers.

This study aimed to examine oxidative effects of both short- and long-term exposure to As in semiconductor workers based on job classification. Strengths of the study included a well-classified population and a well-defined occupational health assessment. This health assessment aimed to assess As exposure by measuring speciated As metabolites in multiple biological matrices (urine, hair, and fingernails) and to determine As methylation efficiency by quantifying both primary and secondary As methylation indexes. Moreover, the study applied two biomarkers (8-OHdG and MDA) to examine oxidative stress from As exposure. The study was innovative because of 1) the use of MDA as an oxidative biomarker, 2) an assessment of As-induced oxidative damage at both systemic and molecular levels; and 3) an association between the oxidative biomarkers and As methylation efficiency.

\section{Materials and Methods}

\subsection{Study Subjects}

A total of 518 non-smoking male workers were recruited from three semiconductor factories in Taiwan in 2014. These human subjects were divided into two groups: an As-exposed group and a control group. The As-exposed group $(n=427)$ consisted of 149 maintenance staff members and 278 production staff members, while the control group included 91 administrative staff members. These exposed subjects were engineers who have engaged in the preventative maintenance procedures, where inorganic As and/or gaseous hydride As were used in the manufacturing process. Our environmental assessment study showed that the administrative staff was exposed to limited As since there were limited inorganic As levels in particulate matter in the office. Only non-smoking subjects were recruited to minimize a confounding effect from cigarette smoking. All of the subjects had been employed in the plants for at least one year. Each participant completed a questionnaire to obtain subject age, height, weight, alcohol consumption, use of personal protection equipment, work history, and lifestyle. The Institute Review Board of the Tri-Service General Hospital, National Defense Medical Center in Taiwan approved this study. All subjects provided informed consent.

\subsection{Biological Sampling}

We collected spot urine, hair, and fingernail samples from all the subjects during a post-work shift over the weekend. Seafood was restricted to all participants for at least 3 days before the collection of biological samples [25]. All participants were asked to wash their hands thoroughly to remove external contamination before biomarker collection. The urine samples were stored at $-20{ }^{\circ} \mathrm{C}$ until analysis. They were prepared by diluting $1 \mathrm{~mL}$ urine with $1 \mathrm{~mL}$ deionized water. A mixed ammonium nitrate matrix modifier was used before As analysis. One-inch long hair samples were collected from the occipital area of the head close to the scalp. The hair samples were washed three times using acetone and then deionized water. They were dried in a clean hood with laminar flow at room temperature for one day. After the hair samples were clean and dry, about $0.1 \mathrm{~g}$ were weighed out and then digested with $14 \mathrm{M}$ nitric acid. Fingernail clippings from all ten fingers were collected from each participant in the study. All participants were asked to wash their hands thoroughly using medicated soap to remove external contamination. Fingernail samples were washed three times by stirring in acetone and then deionized water, separately. These samples were dried for one day in a clean hood with laminar flow 
at room temperature. After the fingernail samples were clean and dry, they were weighed and then digested using $14 \mathrm{M}$ nitric acid, separately.

\subsection{Personal Arsenic Exposure Assessment}

Urine, hair, and fingernail samples were analyzed to determine As species and/or total As exposure to the subjects. Total As concentration in hair and in fingernails were measured using a graphite furnace atomic absorption spectrophotometer (Perkin-Elmer model AAnalyst 800, Norwalk, CT, USA). The detection limits for As in hair and in fingernails were $0.02 \mu \mathrm{g} / \mathrm{g}$ hair and $0.02 \mu \mathrm{g} / \mathrm{g}$ nail, respectively. The coefficients of variation in inter-day and intraday tests were less than $6 \%$ and $8 \%$ for As in hair and in fingernails, respectively. Rh was used as an internal standard for determining As levels. The detection limit for As in urine was $0.09 \mu \mathrm{g} / \mathrm{L}$. The coefficients of variation in inter-day and intraday tests were less than 7\%. Urine samples were analyzed to determine As species, including As(III), As(V), MMA, and DMA. The obtained urine samples were first filtrated with a $0.45-\mu \mathrm{m}$ filter (Millipore, Billerica, MA) to remove insoluble materials. After filtration, $200 \mu \mathrm{L}$ of urine samples were injected into high-performance liquid chromatography (HPLC, JascoPU-1580, CA) for separation of the four different arsenic species. The analytical column used was reversed-phase Nucleosil SB-100A $(250 \times 4.6 \mathrm{~mm}, 10 \mu \mathrm{m}$, Phenomenex, USA). The mobile phase solvent of HPLC consisted of $0.02 \mathrm{M}$ $\mathrm{NaH} 2 \mathrm{PO} 4$ and $0.32 \mathrm{mM} \mathrm{Na} \mathrm{HPO}_{4}$ with a $\mathrm{pH}$ value of 5.2 . The flow rate was set at $1.5 \mathrm{~mL} / \mathrm{min}$. The eluent containing different As species was collected and added individually with $0.5 \mathrm{~mL}$ of $10 \%$ glutathione before the measurement of As concentrations. Five hundred microliters of the eluent mixture were then injected into the flow injection atomic absorption spectrometry (Perkin-Elmer model, AAnalyst 800, Norwalk, CT, USA) for determining concentrations of the four different As species. The carrier gas was nitrogen with a flow rate of $50 \mathrm{~mL} / \mathrm{min}$ while the carrier solution was $0.05 \%$ of $\mathrm{HCl}$. The atomization temperature was $900{ }^{\circ} \mathrm{C}$. The wavelength of the spectrometer for As analysis was set at $193.7 \mathrm{~nm}$. With this method, the recoveries for As(III), As(V), MMA, and DMA were 101\%, 99.6\%, $107 \%$, and $98.7 \%$ while the detection limits were $0.85,1.55,2.8$, and $0.82 \mu \mathrm{g} / \mathrm{L}$, respectively. The batch variabilities for As(III), As(V), MMA, and DMA determinations were 8.5\%, 9.2\%, 5.6\%, and 9.1\%, and between batch variabilities were $7.5 \%, 10.2 \%, 8.2 \%$, and $7.8 \%$, respectively, using a standard solution of $5 \mu \mathrm{g} / \mathrm{L}$. Based on the measurements of urinary arsenic species, PMI and SMI were calculated to assess the enzymatic methylation ability $[4,5]$.

\subsection{Urinary $8-O H d G$}

Urinary 8-OHdG levels were detected employing high-performance liquid chromatography with tandem mass spectrometry (LC-MS/MS), as previously indicated [26]. Twenty microleters of urine was diluted ten-fold using 5\% methanol that contained $0.1 \%$ formic acid. After $40 \mu \mathrm{L}$ of [15N5]-8-OHdG solution $(20 \mu \mathrm{g} / \mathrm{L}$ in $5 \%$ methanol/0.1\% formic acid) was added as an internal standard, $100 \mu \mathrm{L}$ of a prepared urine sample was injected directly into the LC-MS/MS as described above. The precision of this method was evaluated by performing replicate determinations of 8-OHdG levels in three urine samples. The intra- and inter-day coefficients of variation were $2 \%-3 \%$ and $4 \%-5 \%$. A detection limit of $5.7 \mathrm{ng} / \mathrm{L}$ was measured from seven analyses using deionized water. The concentration of urinary 8-OHdG was adjusted to that of urinary creatinine (ng 8-OHdG/mg creatinine) to control for variation in urinary secretion $[26,27]$.

\subsection{Urinary $M D A$}

Urinary MDA concentration was measured using an HPLC (JASCO Model 980-PU, Tokyo, Japan) with a C18 column and an ultraviolet-visible detector at $532 \mathrm{~nm}$ (JASCO UV-975, Tokyo, Japan). The mobile phase was methanol/potassium phosphate (9:11) buffer and the flow rate was $1.2 \mathrm{~mL} / \mathrm{min}$. The within-run and run-to-run precisions of MDA in urine were evaluated. The samples were analyzed for MDA based on a reaction with thiobarbituric acid, with HPLC separation of the MDA (TBA)2 adduct, using tetraethoxypropane as a standard. Precise within-run and run-to-run measurements 
of MDA levels in urine were made. A detection limit of $0.09 \mu \mathrm{g} / \mathrm{L}$ was obtained from seven analyses using deionized water. The coefficient of the within-run and run-to-run precision measurements of MDA levels in urine was less than 9\% [26].

\subsection{Statistical Analysis}

Prior to analysis, the normality of the data distribution was examined. Means and standard deviations were calculated to describe the distribution of demographic data, urinary 8-OHdG, MDA, and various species of As (As(III), As(V), MMA, DMA, and total As) levels in hair and fingernails for the As-exposed group and the control group. Measurements of various As species below the detection limits were assigned as half of the detection limits.

The data were analyzed using SAS statistical package (SAS, version 9.4). Student $t$ statistics were used to compare As species and urinary 8-OHdG, MDA, and other covariates between the As exposed group and the control group. Pearson correlation analysis was used to examine relationships of the concentrations of biomarkers for oxidative stress (urinary 8-OHdG and MDA) and the values of As methylation indexes (MMA and PMI) with controlling for other variables, e.g., age, BMI, alcohol consumption, and other potential chemical exposures.

Linear mixed-effect regression models were used to determine predictors of workers' levels of oxidative stress, since the models enable estimation of between- and within-worker variance components of exposure levels while accounting for the fixed effects of work conditions. Consequently, work conditions affecting oxidative stress levels can be identified. In linear mixed-effect regression models, urinary 8-OHdG, MDA, and various species of As concentrations were log10-transformaed to normalize its distribution. The subjects' age, BMI, work history, degree of exposure to secondhand smoke, alcohol consumption, total As levels in urine, hair, and fingernail samples, and As species concentrations in urine were treated as fixed effects, while each semiconductor area was treated as a random effect in the data analysis. In all tests, the standard level for statistical significance was set to $\alpha=0.05$.

\section{Results}

\subsection{As Levels in Study Subjects}

Table 1 provides the demographic characteristics of the As-exposed group and the control group. Work history, alcohol consumption, and potential chemical exposure (isopropanol and acetone) are also provided in Table 1 . The study subjects were 35 years old on average. The mean BMI of the maintenance staff $\left(23.9 \mathrm{~kg} / \mathrm{m}^{2}\right)$ was significantly higher than those of the production staff $\left(23.5 \mathrm{~kg} / \mathrm{m}^{2}\right)$ and control subjects $\left(22.5 \mathrm{~kg} / \mathrm{m}^{2}\right)$. Both of the work hours per day of the maintenance staff and production staff were significantly higher than that of control subjects. The potential chemical exposures for the maintenance staff and production staff were significantly higher than that of control subjects.

Table 1. Descriptive statistics for non-smoking workers by job title in three semiconductor plants.

\begin{tabular}{cccc}
\hline Variable & $\begin{array}{c}\text { Control Subjects } \\
(\mathbf{n}=\mathbf{9 1 )}\end{array}$ & $\begin{array}{c}\text { Production Staff } \\
(\mathbf{n}=\mathbf{2 7 8 )}\end{array}$ & $\begin{array}{c}\text { Maintenance Staff } \\
(\mathbf{n}=\mathbf{1 4 9 )}\end{array}$ \\
\hline Age (years) & $36.2 \pm 5.8$ & $34.5 \pm 4.9$ & $34.1 \pm 3.6$ \\
Height $(\mathrm{cm})$ & $170.0 \pm 5.6$ & $169.5 \pm 4.6$ & $170.2 \pm 6.4$ \\
Weight $(\mathrm{kg})$ & $65.3 \pm 9.3$ & $64.8 \pm 7.7$ & $69.4 \pm 9.8^{*+}$ \\
Body mass index (kg/m $\left.{ }^{2}\right)$ & $22.5 \pm 2.2$ & $22.5 \pm 2.5$ & $23.9 \pm 2.8^{*+}$ \\
Work years (years) & $9.5 \pm 2.6$ & $10.0 \pm 2.5$ & $10.1 \pm 1.9$ \\
Workdays per week (days) & $4.8 \pm 1.0$ & $4.5 \pm 0.8$ & $4.8 \pm 0.6$ \\
Work hours per day (hours) & $8.9 \pm 2.3$ & $10.1 \pm 1.9^{\#}$ & $9.6 \pm 1.5^{*}$ \\
Alcohol consumption & $27(29.6 \%)$ & $82(29.4 \%)$ & $61(40.9 \%)$ \\
Potential chemical exposure \& & $25(27.5 \%)$ & $196(70.5 \%)$ & $90(60.4 \%)^{*}$ \\
\hline
\end{tabular}

* Maintenance staff/production staff differ significantly from control subjects at $p<0.05 .{ }^{+}$Maintenance staff differ significantly from production staff at $p<0.05$. \# Production staff differ significantly from control subjects at $p<0.05$.

\& Chemicals include isopropanol and acetone. 
Table 2 shows geometric mean (GM) concentrations of As(III), As(V), MMA, and DMA in urine of the As-exposed group and the control group. Furthermore, total As concentrations of both hair and nail samples are included. The GM concentration of total As in hair of the As-exposed group was significantly higher than that of the control group $(p<0.001)$. Among the As-exposed group, the GM concentration of total As in hair of the maintenance staff was significantly higher than that of the production staff $(p<0.05)$. A similar result was observed for the total As in fingernail samples. The GM concentration of total As in fingernails of the As-exposed group was significantly higher than that of the control group ( $p<0.001)$. In addition, the GM concentration of total As in fingernails of the maintenance staff was significantly higher than that of the production staff $(p<0.05)$. The GM concentration of total As in urine of the As-exposed group was significantly higher than that of the control group $(p<0.001)$.

Table 2. Oxidative stress biomarkers and arsenic (As) in biological specimens from As-exposed workers and control subjects.

\begin{tabular}{|c|c|c|c|}
\hline Variable & $\begin{array}{c}\text { Control Subjects } \\
(\mathrm{n}=91)\end{array}$ & $\begin{array}{l}\text { Production Staff } \\
\quad(n=278)\end{array}$ & $\begin{array}{l}\text { Maintenance Staff } \\
\quad(\mathrm{n}=149)\end{array}$ \\
\hline & \multicolumn{3}{|c|}{ Geometric mean (geometric standard deviation) } \\
\hline 8-OHdG ( $\mu \mathrm{g} / \mathrm{L}$ creatinine) & $3.9(2.1)$ & $5.2(1.8) *$ & $7.6(1.9) *+$ \\
\hline MDA ( $\mu \mathrm{g} / \mathrm{L}$ creatinine) & $119.7(2.1)$ & $161.8(1.9) *$ & $171.9(2.3)$ * \\
\hline $\operatorname{As}(\mathrm{III})(\mu \mathrm{g} / \mathrm{L})$ & $0.7(2.3)$ & $0.9(2.4)$ & $2.4(3.2)^{*}$ \\
\hline $\operatorname{As}(V)(\mu g / L)$ & $0.9(2.1)$ & $1.0(2.1)$ & $2.7(2.6) *{ }^{*}$ \\
\hline MMA $(\mu \mathrm{g} / \mathrm{L})$ & $1.7(2.1)$ & $1.9(2.1)$ & $3.6(2.9) *+$ \\
\hline DMA $(\mu \mathrm{g} / \mathrm{L})$ & $11.2(2.0)$ & $16.2(1.9)^{*}$ & $24.1(2.1)^{* \dagger}$ \\
\hline $\mathrm{iAs}(\mu \mathrm{g} / \mathrm{L})^{\mathrm{a}}$ & $1.8(1.8)$ & $2.3(2.0)$ & $4.3(2.2) * \dagger$ \\
\hline Total As $(\mu \mathrm{g} / \mathrm{L})^{\mathrm{b}}$ & $15.8(1.8)$ & $21.1(1.8)^{*}$ & $34.5(2.1) * \dagger$ \\
\hline PMI (MMA/iAs) & $1.2(1.7)$ & $1.4(1.9)$ & $2.3(2.1) *+$ \\
\hline SMI (DMA/MMA) & $7.9(4.5)$ & $12.5(5.1)$ & $14.8(4.9)^{* \dagger}$ \\
\hline Hair As (ng/g) & $20.1(8.9)$ & $48.2(3.2) *$ & $82.8(7.7) *$ \\
\hline Fingernail As $(\mu \mathrm{g} / \mathrm{g})$ & $94.2(2.5)$ & $218.1(3.4) *$ & $354.9(3.6) *$ \\
\hline
\end{tabular}

${ }^{*}$ Maintenance staff/production staff differ significantly from control subjects at $p<0.05 .{ }^{\dagger}$ Maintenance staff differ significantly from production staff at $p<0.05$. ${ }^{\mathrm{a}}$ iAs: As(III) $+\mathrm{As}(\mathrm{V}) .{ }^{\mathrm{b}}$ Total As: As(III) + As(V) + MMA + DMA.

The maintenance staff had significantly higher GM concentrations of As(III), As(V), and MMA than those of both production staff and control subjects $(p<0.001)$. Both the maintenance staff and production staff had significantly higher GM concentrations of DMA than those of control subjects $(p<0.05)$.

The maintenance staff had a higher GM value of PMI (2.3) than the production staff (1.4) and control subjects (1.2) $(p<0.05)$. Both of the GM values of SMI in the maintenance staff (14.8) and production staff (12.5) were significantly higher than that of control subjects $(7.9)(p<0.05)$.

The GM concentrations of urinary $8-\mathrm{OHdG}$ and MDA for the As-exposed group and the control group are tabulated in Table 2. Both GMs of urinary 8-OHdG concentrations for the maintenance staff $(7.6 \mu \mathrm{g} / \mathrm{L}$ creatinine $)$ and production staff $(5.2 \mu \mathrm{g} / \mathrm{L}$ creatinine $)$ significantly exceeded that of control subjects $(4.1 \mu \mathrm{g} / \mathrm{L})(p<0.05)$. A similar result occurred in MDA. The GM of urinary MDA concentrations of the maintenance staff $(7.6 \mu \mathrm{g} / \mathrm{L}$ creatinine $)$ and production staff $(5.2 \mu \mathrm{g} / \mathrm{L}$ creatinine $)$ were also significantly higher than that of control subjects $(3.9 \mu \mathrm{g} / \mathrm{L}$ creatinine $)(p<0.05)$. The GM of urinary 8-OHdG concentration of the maintenance staff was higher than that of production staff. However, the GM of urinary MDA concentrations did not differ significantly between the maintenance staff and production staff.

\subsection{As Exposure Evaluation}

The results from fully adjusted linear mixed-effect analyses on urinary total As and worksite and work history are shown in Table 3. Urinary total As concentrations were significantly associated with 
worksite and work hours per day after adjusting for covariates. Those covariates included alcohol consumption, potential chemical exposure, age, and BMI. Number of work years was a statistically positive predictor of total As concentrations in both hair and fingernails. Worksite and work hours per day were positively correlated with urinary total As, which is the sum of $\mathrm{As}(\mathrm{III}), \mathrm{As}(\mathrm{V}), \mathrm{MMA}$, and DMA. This suggested that urinary total As could serve as a biomarker for recent As exposure. Worksite and number of work years were two positive predictors of total As concentrations in both hair and fingernails. This indicated that both hair and fingernail As are suitable biomarkers for chronic, cumulative As exposure.

\subsection{Biomarkers of Oxidative Stress Assessment}

Table 4 presents the results from linear mixed-effects regression models constructed to evaluate predictors of urinary 8-OHdG and MDA concentrations in the participants. Worksite, work hours per day, and urinary total As concentrations were significantly associated with urinary 8-OHdG concentrations after adjusting for the covariates. Urinary total As concentrations were positively correlated with urinary 8-OHdG concentrations $(p<0.05)$. A ten-fold increase in urinary total As concentrations was associated with a 1.47 -fold increase in urinary 8 -OHdG concentrations $\left(10^{0.167}=1.47\right)$. However, alcohol consumption, potential chemical exposure, age, work years, workdays per week, BMI, inorganic As concentrations in urine, hair, and fingernail were not significantly associated with urinary 8-OHdG concentrations.

Worksite was significantly associated with urinary MDA concentrations following controlling for the covariates. However, alcohol consumption, potential chemical exposure, age, work years, workdays per week, work hours per day, and BMI were not significantly correlated with urinary MDA concentrations. Moreover, concentrations of urinary $\mathrm{As}(\mathrm{III}), \mathrm{As}(\mathrm{V})$, and total As were not significantly correlated with urinary MDA concentrations. Finally, As concentrations in both hair and fingernails were not significantly correlated with urinary MDA concentrations. 
Table 3. Assessment of predictors of urinary As, hair As, and fingernail As in semiconductor workers using linear mixed-effect regression analysis.

\begin{tabular}{|c|c|c|c|c|c|c|}
\hline \multirow{2}{*}{ Variables } & \multicolumn{2}{|c|}{$\log _{10}$ Urinary Total As $(\mu \mathrm{g} / \mathrm{L})$} & \multicolumn{2}{|c|}{$\log _{10}$ Hair As $(\mu \mathrm{g} / \mathrm{g})$} & \multicolumn{2}{|c|}{$\log _{10}$ Fingernail As $(\mu \mathrm{g} / \mathrm{g})$} \\
\hline & Regression Coefficient & $95 \% \mathrm{CI}$ & Regression Coefficient & $95 \% \mathrm{CI}$ & Regression Coefficient & $95 \% \mathrm{CI}$ \\
\hline Work site & & & & & & \\
\hline Production staff vs. control subjects & 0.189 & $0.297-0.478$ * & 0.240 & $0.112-0.368 *$ & 0.419 & $0.222-0.617$ * \\
\hline Alcohol consumption $(\mathrm{y} / \mathrm{n})$ & -0.004 & $-0.059-0.052$ & 0.033 & $-0.132-0.198$ & 0.048 & $-0.085-0.180$ \\
\hline Potential chemical exposure $(\mathrm{y} / \mathrm{n})^{+}$ & -0.022 & $-0.079-0.036$ & 0.048 & $-0.123-0.219$ & -0.046 & $-0.184-0.092$ \\
\hline Work years (years) & 0.010 & $-0.003-0.022$ & 0.029 & $0.012-0.046^{*}$ & 0.070 & $0.007-0.133$ * \\
\hline Workdays per week (days) & 0.054 & $-0.004-0.111$ & 0.124 & $-0.035-0.284$ & 0.038 & $-0.092-0.169$ \\
\hline Work hours per day (hours) & 0.039 & $0.001-0.045 *$ & 0.040 & $-0.023-0.103$ & 0.011 & $-0.042-0.063$ \\
\hline Age (years) & 0.003 & $-0.003-0.009$ & 0.002 & $-0.034-0.039$ & 0.003 & $-0.011-0.180$ \\
\hline BMI $\left(\mathrm{kg} / \mathrm{m}^{2}\right)$ & -0.002 & $-0.011-0.007$ & -0.010 & $-0.037-0.016$ & 0.005 & $-0.016-0.199$ \\
\hline
\end{tabular}


Table 4. Multiple linear mixed-effects regression analysis: predictors of urinary 8-hydroxy-2'-deoxyguanosine (8-OHdG) and malondialdehyde (MDA) in non-smoking male semiconductor workers.

\begin{tabular}{|c|c|c|}
\hline Parameters & $\begin{array}{c}\log _{10} 8-\mathrm{OHdG}(\mu \mathrm{g} / \mathrm{g} \\
\text { Creatinine) }\end{array}$ & $\log _{10}$ MDA ( $\mu \mathrm{g} / \mathrm{g}$ Creatinine) \\
\hline Predictors & $\begin{array}{c}\text { Regression Coefficient } \\
\text { (95\% Confidence Interval) }\end{array}$ & $\begin{array}{l}\text { Regression Coefficient } \\
\text { (95\% Confidence Interval) }\end{array}$ \\
\hline \multicolumn{3}{|l|}{ Worksite } \\
\hline Production staff vs. control subjects & $0.124(0.018-0.230) *$ & $0.178(0.035-0.322) *$ \\
\hline Maintenance staff vs. control subjects & $0.210(0.087-0.332) *$ & $0.246(0.121-0.370)$ * \\
\hline Alcohol consumption $(\mathrm{y} / \mathrm{n})$ & $0.002(-0.068-0.072)$ & $0.026(-0.056-0.108)$ \\
\hline Potential chemical exposure $(\mathrm{y} / \mathrm{n})$ & $0.039(-0.033-0.110)$ & $0.004(-0.080-0.088)$ \\
\hline Work years (years) & $0.008(-0.011-0.026)$ & $0.010(-0.011-0.031)$ \\
\hline Workdays per week (days) & $0.009(-0.023-0.041)$ & $0.060(-0.031-0.043$ \\
\hline Work hours per day (hours) & $0.018(0.001-0.035)$ * & $0.001(-0.021-0.022)$ \\
\hline Age (years) & $-0.003(-0.011-0.005)$ & $0.004(-0.005-0.013)$ \\
\hline BMI $\left(\mathrm{kg} / \mathrm{m}^{2}\right)$ & $0.007(-0.004-0.018)$ & $-0.009(-0.022-0.004)$ \\
\hline $\log _{10}$ iAs $(\mu \mathrm{g} / \mathrm{L})$ & $0.002(-0.007-0.010)$ & $0.009(-0.001-0.019)$ \\
\hline $\log _{10}$ Urinary total As $(\mu \mathrm{g} / \mathrm{L})$ & $0.167(0.010-0.3325) *$ & $0.004(-0.181-0.188)$ \\
\hline $\log _{10}$ Hair As $(\mu \mathrm{g} / \mathrm{g})$ & $0.018(-0.040-0.075)$ & $0.044(-0.024-0.112)$ \\
\hline $\log _{10}$ Fingernail As $(\mu \mathrm{g} / \mathrm{g})$ & $0.065(-0.007-0.137)$ & $0.003(-0.081-0.088)$ \\
\hline
\end{tabular}

Urinary 8-OHdG concentrations in As-exposed semiconductor workers were about three times higher than in the control subjects. Urinary $8-\mathrm{OHdG}$ concentrations of exposed semiconductor workers were positively associated with urinary MMA concentrations as shown in Figure $1(p<0.001$, $n=427)$. The greater urinary excretion of MMA, the higher the concentrations of urinary 8-OHdG. Urinary MDA concentrations of the As-exposed group were not significantly correlated with urinary MMA concentrations $(p=0.169, \mathrm{n}=427)$.

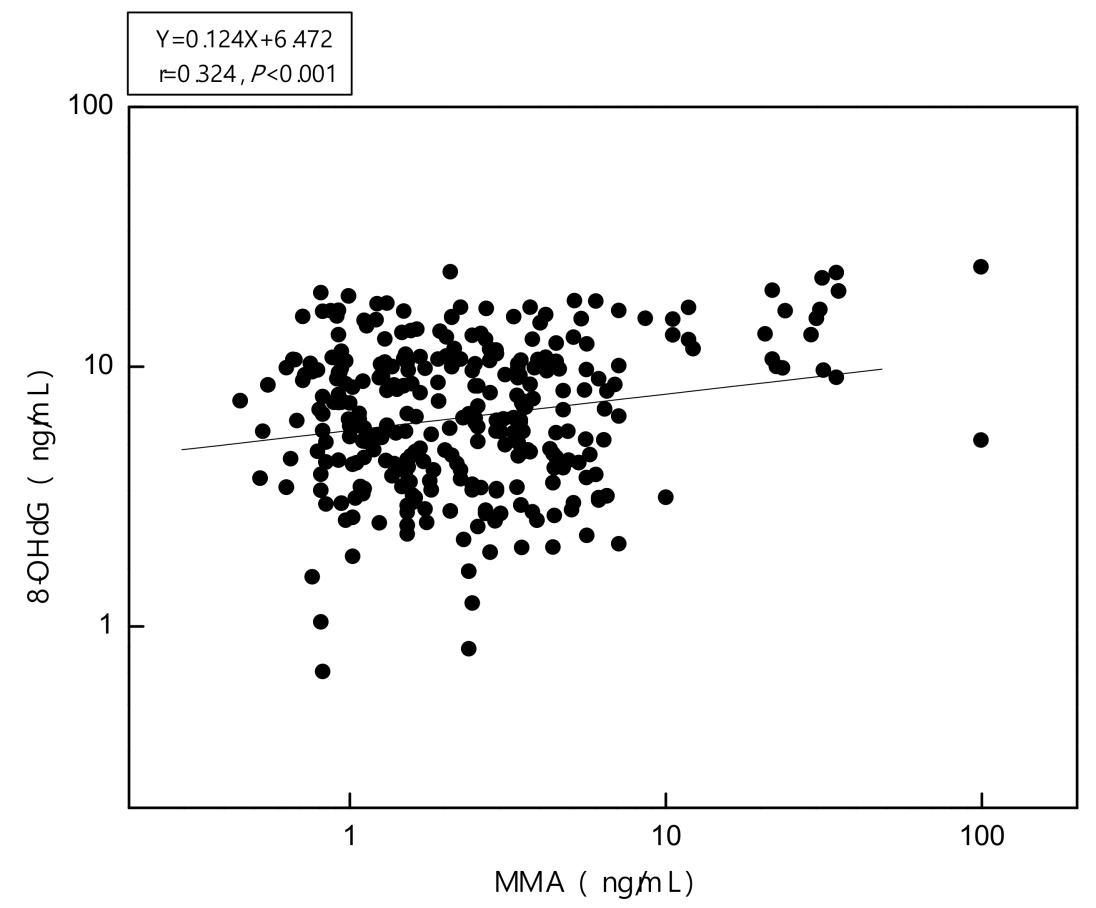

Figure 1. Relationship between urinary 8-OHdG and monomethylarsonic (MMA) among 427 As-exposed workers.

Urinary 8-OHdG concentrations in the As-exposed group were positively associated with the values of PMI as shown in Figure $2(p<0.001, \mathrm{n}=427)$. However, urinary MDA concentrations of 
the As-exposed group were not significantly correlated with the values of PMI $(p=0.058, \mathrm{n}=427)$. Urinary 8-OHdG concentrations in the As-exposed group were not significantly associated with SMI $(p=0.582, \mathrm{n}=427)$. Furthermore, urinary MDA concentrations in the As-exposed group were also not significantly associated with SMI $(p=0.225, \mathrm{n}=427)$.

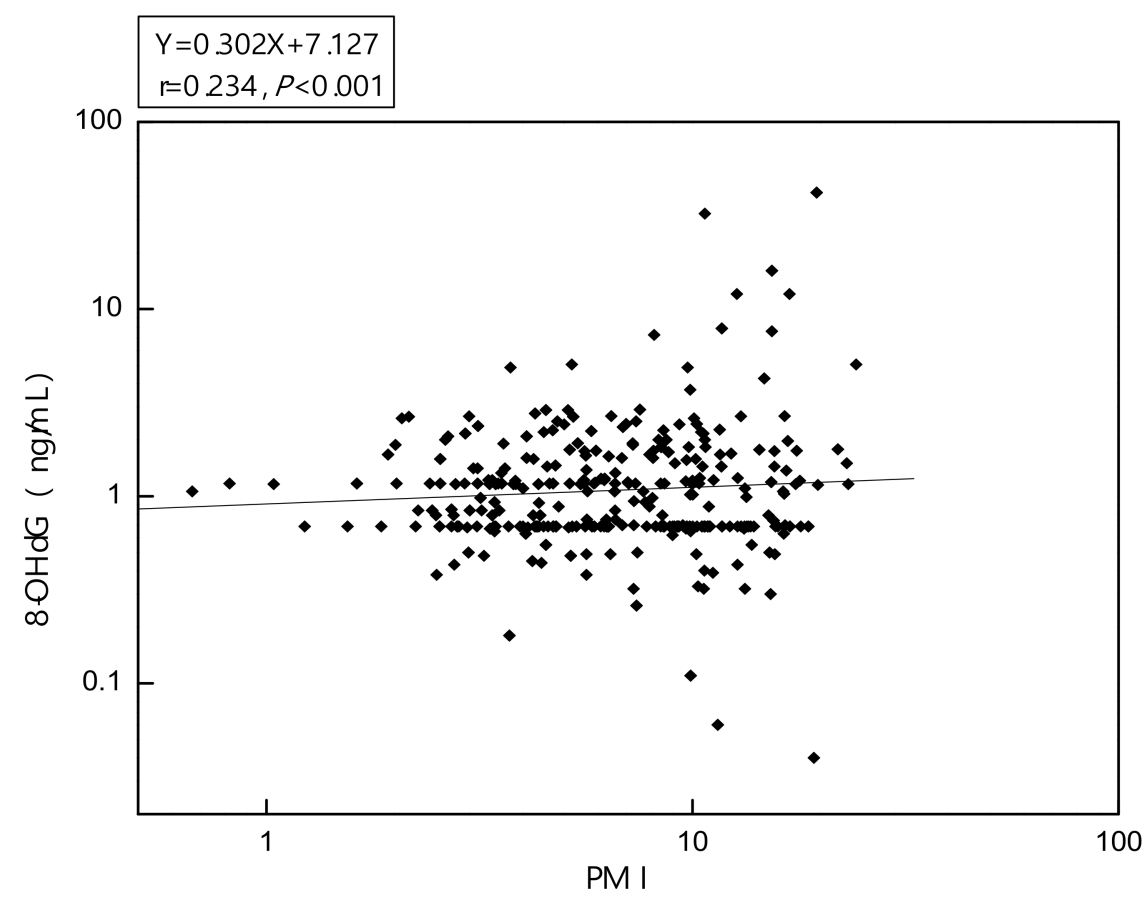

Figure 2. Relationship between urinary 8-OHdG and primary methylation index (PMI) among 427 As-exposed workers.

\section{Discussion}

Due to the nature of the semiconductor manufacturing process, semiconductor workers are in a high-risk occupational group for exposure to As and for developing As-induced health hazards. There is a need to examine modifiers and/or predictors of aggregated health effects of the semiconductor workers and to produce more scientific evidence to gain a better understanding of As-related disease risk and the metabolic mode of toxicokinetics of As.

This study included several strengths. First, an occupational exposure assessment was well designed to assess both recent and chronic exposures to As in semiconductor workers by using three biological matrices-urine, hair, and fingernails-from each participant. Second, human subjects were categorized based on worksites to distinguish different levels of As for a qualitative ordinal ranking of exposure. Third, internal dose and biological effective dose biomarkers were analyzed simultaneously to elucidate As metabolism pathways, As-induced toxicity, and the possible increased risk of oxidative stress-related disease.

The occupational exposure assessment was designed to quantify concentrations of total As, As species, and methylated As metabolites in maintenance staff, production staff, and control subjects in the semiconductor plants. The maintenance staff had been exposed to higher concentrations of total As, $\mathrm{As}(\mathrm{III})$, and $\mathrm{As}(\mathrm{V})$ in urine than those in both the production staff and control group. Subsequently, the maintenance staff experienced higher concentrations of methylated As in urine than other study subjects. The results indicate that the maintenance staff who is regularly involved in maintenance and cleaning processes had a higher potential for occupational exposure to As than other groups of semiconductor workers who are involved in routine production work. Byun et al. observed similar findings in As exposure based on job classification. Comparing other groups of semiconductor workers, maintenance engineers in cleaning processes are exposed to the highest concentration of As, 
particularly those engineers who performed various maintenance works inside an ion implantation chamber [20]. Wipe samples in the process area suggested that As particulate matter becomes airborne in the chamber and is easily inhaled by the workers [11,23]. Applications of As in the ion implantation process and cleaning and maintenance of the equipment contaminated with As constitute occupational health hazards to semiconductor workers.

In comparison with other studies, the GM of the total As concentrations in urine of the maintenance staff was $34.5 \mu \mathrm{g} / \mathrm{L}$, which was comparable with the GM of urinary total As concentrations of $32.48 \mu \mathrm{g} / \mathrm{L}$ in our prior study [6]. Furthermore, the maintenance staff's total As concentrations fell within the range of the GM of the As concentrations of $28.95 \mu \mathrm{g} / \mathrm{L}$ and $51.32 \mu \mathrm{g} / \mathrm{L}$ for ion implantation staff and cleaning staff, respectively, reported by Byun et al. [6]. On the other hand, Hwang et al. observed a lower urinary As level of $29.5 \pm 17.2 \mu \mathrm{g} / \mathrm{L}$ for 30 engineers from six semiconductor facilities [3]. Composition of different semiconductor work groups may contribute to the lower urinary As level. Due to the rapid metabolism of $\mathrm{As}(\mathrm{V})$ to $\mathrm{As}(\mathrm{III})$ in the biological system, Byun et al. [6] reported that $\mathrm{As}(\mathrm{III})$ concentrations were higher than $\mathrm{As}(\mathrm{V})$ in urine from semiconductor workers. It remains unclear why elevated As(V) concentrations in the semiconductor workers of the study were higher than As(III) concentrations.

As part of the occupational exposure assessment, we employed As measurements in human urine, hair, and fingernails as biomarkers of internal doses of As. Although a majority of inorganic and organic As is readily excreted from the body within hours or a couple of days, some organic and inorganic As remain in the body for a number of months or even longer [28]. The toxicokinetics of As excretion is evident in the observed correlations between As levels in biological matrices and work periods. The work periods served as an index for a timeframe of As exposure in this study. Due to its rapid excretion after exposure, it is anticipated that creatinine-corrected urinary As concentrations positively correlated with a worker's workdays (Table 4). On the other hand, the positive correlations between total As levels in hair and fingernails and a worker's work years suggested that some organic and inorganic As gradually accumulated in the biological system. The stronger correlation between the number of years worked and total As concentrations in fingernails added additional evidence that fingernails may accumulate As for a longer period than urine and hair do. Hair grows continuously at $2.9 \mathrm{~mm}$ per week while fingernails grow more slowly at $0.05-1.2 \mathrm{~mm}$ per week [13]. Overall, our results support that total As concentrations in hair and fingernails reflect an accumulated, chronic As exposure. The accumulation of As in fingernails and hair, together with its advantages in non-invasive sampling, made both biological matrices attractive biomarkers for intake assessment of chronic As exposure, whereas creatinine-corrected urinary As in spot urine samples can be routinely used in monitoring workers recently exposed to inorganic As in a large scale human study. However, fingernail and hair samples do not perform as well as urinary samples to measure oxidative stress.

Methylated organic As is generally considered to be less toxic than the inorganic form since methylation has long been considered to be a process of detoxification for enhancing excretion of As [18,19]. However, recent research of As metabolism has changed our understanding of the modulation of toxicity and carcinogenicity of As [12]. Increasing mechanistic studies have indicated that the methylation pathway of As is a bioactivation process rather than detoxification, because the methylation processes may lead to form reactive and carcinogenic trivalent methylated arsenicals. Methylated As metabolites (MMA(V) and DMA(V)) have been found to link to incidences of bladder, kidney, and liver cancer. Considering the health risks linked to methylated As metabolites, methylation pathway and tendency have been examined in research to provide a better understanding of As toxicity and its health impacts.

PMI and SMI have been used to describe the methylation tendency in humans. The maintenance staff in this study had a GM PMI of 2.5 that was higher than As-exposed smelter workers (PMI = 1.3) [29]. Moreover, the GM PMI for the maintenance staff was higher than the GMs of PMI (0.4-2.3) from different population groups in the world (California, China, Chile, and Nevada) [30]. However, the GM of the PMI of the maintenance staff in this study was similar to subjects in a blackfoot disease-endemic 
area where PMIs ranged between 2.3 and 5.2 [4,5]. Comparing the GM SMIs (2.0-10.6) of other high As-exposed subjects, both the production staff $(\mathrm{SMI}=11.7)$ and maintenance staff $(\mathrm{SMI}=13.2)$ in the study had higher GMs of SMI [4,31]. Due to the unstable state and rapidly oxidation, measurements of MMA(III) and DMA(III) in urine were not included in this study. It is possible that the relatively high content of MMA(V) in urine observed in the maintenance staff could reflect the higher MMA(III) in blood. Nonetheless, the observed high values of SMI indicated that most MMA(V) in the body was transformed into MDA after being exposed to inorganic As.

Extensive epidemiological and experimental evidence suggest that oxidative stress is the primary mechanism for the toxicity of arsenic. $8-\mathrm{OHdG}$ is the predominant form of free radical-induced oxidative lesions and is a widely used biomarker for measuring the effect of endogenous oxidative damage to DNA [32]. Modified 2'deoxyribonucleoside (8-oxodGuo) in urine is the major repair product of oxidatively damaged DNA in vivo, presumably formed by nucleotide excision repair and sanitization of the DNA precursor 2'-deoxyribonucleotide pool [33]. During DNA sample preparation, artifactual oxidation of the samples may also occur, especially in the presence of a large excess of native nucleosides, e.g., DNA hydrolysates, in the samples. One study reported that the artifactual formation of 8-oxodGuo from dG during DNA preparation may yield 30 micromol per mole of dG without the addition of antioxidants [26]. However, the concentration of native urinary dG in our urinary analysis ranged from 1.3 to $5.2 \mathrm{ng} / \mathrm{mL}$, which range is similar to that of 8-oxodGuo [33,34]. Thus, the native urinary $\mathrm{dG}$ is reasonably inferred to be too low to cause significant artifactual oxidation during sample preparation.

Our study showed that both the high As-exposed production staff and maintenance staff experienced significantly elevated concentrations of urinary 8-OHdG and MDA compared with the control subjects. In addition, urinary 8-OHdG positively correlated with worksites. Furthermore, positive correlations of urinary total As and urinary 8-OHdG in As-exposed semiconductor workers occurred in multiple linear regression analyses. Together, our results supported that exposure to As increased genetically oxidative lesions and systemic oxidative stress in semiconductor workers. The study did not examine molecular mechanisms for 8-OHdG elevation. Whatever the mechanisms, the increased urinary 8-OHdG could serve as an indicator of aggravated genotoxic lesions after As exposure. It is worth noting that As concentrations in fingernails and hair were not correlated with urinary 8-OHdG concentrations. That may be due to the notion that urinary 8-OHdG acted as a short-term biomarker of oxidative stress, while As concentrations in fingernails and hair reflect long-term exposure to As. Half-life of induced urinary 8-OHdG approximately ranged from six to seven hours [35].

Covariances were considered when multiple regression analyses were conducted to determine correlations between oxidative stress biomarkers and exposure to As. BMI and alcohol consumption did not significantly affect urinary $8-\mathrm{OHdG}$ concentrations. The findings differed from a previous study, reporting that urinary $8-\mathrm{OHdG}$ concentrations may be influenced by BMI and alcohol consumption [36].

As methylation capacity was evaluated to determine its role in As-induced oxidative effects. Urinary 8-OHdG levels in semiconductor workers positively correlated with both MMA levels and PMI levels. Our results support that MMA may be a toxic metabolite being involved in the induction of oxidative stress. Moreover, the results suggest that the oxidation state of the methylated arsenicals is important in the manifestation of As cytotoxic and genotoxic effects. Our study's findings were consistent with Hu's [23] finding that increased MMA concentrations in semiconductor workers positively correlated with urinary $8-\mathrm{OHdG}$. However, the study in $\mathrm{Hu}$ et al. [23] did not include multiple biological matrices, including fingernails and hair, to evaluate long-term health effects from As exposure. Furthermore, Hu's study did not evaluate the correlation between urinary As species and MDA and did not assess oxidative stress effects for long-term exposure to As in semiconductor workers. Li et al. [37] reported that the Chinese residents exposed to high-As through coal burning had increased urinary $8-\mathrm{OHdG}$ concentrations compared to that of low exposed residents. The urinary 8-OHdG concentrations were positively correlated with concentrations of As, MMA, and DMA. 
An epidemiological study by Fujino et al. [38] reported correlations between MMA and As dermatosis of the subjects living in a high-arsenic-affected village. The MMA in the subjects with arsenic dermatosis was positively correlated with urinary 8-OHdG.

MDA has been used to serve as a biomarker for systemic oxidative stress. We found that MDA concentrations were positively associated with worksites. That suggests that the maintenance staff had higher MDA concentrations than the production staff. However, MDA concentrations were not significantly correlated with As, MMA, MDA, and total As in urine, hair, and fingernails. MDA may not be a sensitive biomarker for oxidative stress induced by As exposure, As species, and methylated arsenicals. The lack of sensitivity could stem from its readiness to react with other substances in the body. Moreover, MDA reflects lipid peroxidation rather than DNA oxidation. 8-OHdG could serve as a more reliable biomarker for predicting As methylation than MDA did. MDA concentration is regarded as a systemic oxidative stress indicator. However, MDA reacts readily with other substances in the body, and its level, unlike that of urinary $8-\mathrm{OHdG}$, may not accurately reflect oxidative stress throughout the whole body.

This study has certain limitations. Some metals, e.g., nickel, titanium, and aluminum, were not measured. These metals are used in doping silicon wafers processing. Semiconductor workers might come in contact with them. Another limitation was that the study's analytical procedures did not include measurements of As concentrations in erythrocytes, which would be an important measure of systemic exposure to As. Regardless of the limitations, the well-designed exposure assessment and measurement of biological effective dose and internal dose biomarkers under controlling for multiple covariances have still yielded valuable findings to gain a better understanding of As methylation and toxicity. Furthermore, the findings support that urinary total As could serve as a suitable predictor for urinary 8-OHdG concentrations in semiconductor workers. Finally, exposure to As increased the risk of oxidative DNA damage among semiconductor workers.

\section{Conclusions}

As exposure increased oxidative stress in semiconductor workers. Urinary 8-OHdG served as a more reliable biomarker for assessing oxidative stress induced by As exposure as compared to MDA, a biomarker for systemic oxidative stress. Urinary total As and 8-OHdG concentrations reflected As methylation efficiency. Increased concentrations of As in these humans' biological matrices warrant a need to develop proper preventive measures, including adequate ventilation and the use of personal protection equipment (gloves and respirators) to protect the health of semiconductor workers.

Author Contributions: C.-H.P. and C.-Y.L. designed the research. C.-H.L. conducted the data collection. C.-H.P. analyzed the biological samples. The manuscript was mainly drafted by C-H.P., C.-Y.L., and H.A.J.. H.A.J. critically revised this manuscript to improve its intellectual contents. All authors have read and agreed to the published version of the manuscript.

Funding: This research was funded by the Institute of Labor, Occupational Safety and Health, Ministry of Labor, Taiwan, grant number ILOSH103-A322.

Acknowledgments: The authors would like to thank the Institute of Labor, Occupational Safety and Health, Ministry of Labor, Taiwan, for financially supporting this research under Contract No. ILOSH103-A322.

Conflicts of Interest: The authors declare no conflict of interest.

\section{References}

1. Williams, M.E.; Baldwin, D.G. (Eds.) Semiconductor Industrial Hygiene Handbook; Noyes: Park Ridge, NJ, USA, 1994.

2. De Peyster, A.; Silvers, J.A. Arsenic levels in hair of workers in a semiconductor fabrication facility. Am. Ind. Hyg. Assoc. J. 1995, 56, 377-383. [CrossRef] [PubMed]

3. Hwang, Y.H.; Lee, Z.Y.; Wang, J.D.; Hsueh, Y.M.; Lu, I.C.; Yao, W.L. Monitoring of arsenic exposure with speciated urinary inorganic arsenic metabolites for ion implanter maintenance engineers. Environ. Res. 2002, 90, 207-216. [CrossRef] 
4. Chen, Y.C.; Guo, Y.L.; Su, H.J.; Hsueh, Y.M.; Smith, T.J.; Ryan, L.M.; Lee, M.S.; Chao, S.C.; Lee, J.Y.; Christiani, D.C. Arsenic methylation and skin cancer risk in southwestern Taiwan. J. Occup. Environ. Med. 2003, 45, 241-248. [CrossRef] [PubMed]

5. Chen, Y.C.; Su, H.J.; Guo, Y.L.; Hsueh, Y.M.; Smith, T.J.; Ryan, L.M.; Lee, M.-S.; Christiani, D. Arsenic methylation and bladder cancer risk in Taiwan. Cancer Causes Control 2003, 14, 303-310. [CrossRef] [PubMed]

6. Byun, K.; Won, Y.L.; Hwang, Y.I.; Koh, D.H.; Im, H.; Kim, E.A. Assessment of arsenic exposure by measurement of urinary speciated inorganicarsenic metabolites in workers in a semiconductor manufacturing plant. Ann. Occup. Environ. Med. 2013, 25, 21. [CrossRef]

7. Apostoli, P.; Bartoli, D.; Alessio, L.; Buchet, J.P. Biological monitoring of occupational exposure to inorganic arsenic. Occup. Environ. Med. 1999, 56, 825-832. [CrossRef]

8. Zaprianov, Z.; Tsalev, D.; Georgieva, R.; Kaloianova, F.; Nikolova, V. New toxicokinetic exposure tests for metals based on atomic absorption analysis of the fingernails. Probl. Khigi. 1989, 14, 75-97.

9. Loffredo, C.A.; Aposhian, H.V.; Cebrian, M.E.; Yamauchi, H.; Silbergeld, E.K. Variability in human metabolism of arsenic. Environ. Res. 2003, 92, 85-91. [CrossRef]

10. Huang, Y.L.; Hsueh, Y.M.; Huang, Y.K.; Yip, P.K.; Yang, M.H.; Chen, C.J. Urinary arsenic methylation capability and carotid atherosclerosis risk in subjects living in arsenicosis-hyperendemic areas in southwestern Taiwan. Sci. Total Environ. 2009, 407, 2608-2614. [CrossRef]

11. Park, D.; Yang, H.; Jeong, J.; Ha, K.; Choi, S.; Kim, C.; Yoon, C.; Park, D.; Paek, D. A comprehensive review of arsenic levels in the semiconductor manufacturing industry. Ann. Occup. Hyg. 2010, 54, 869-879.

12. Kitchin, K.T. Recent advances in arsenic carcinogenesis: Modes of action, animal model systems, and methylated arsenic metabolites. Toxicol. Appl. Pharmacol. 2001, 172, 249-261. [CrossRef] [PubMed]

13. Yager, J.W.; Hicks, J.B.; Fabianova, E. Airborne arsenic and urinary excretion of arsenic metabolites during boiler cleaning operations in a Slovak coal-fired power plant. Environ. Health Perspect. 1997, 105, 836-842. [CrossRef] [PubMed]

14. Abdulrahman, F.I.; Akan, J.C.; Chellube, Z.M.; Waziri, M. Levels of Heavy Metals in Human Hair and Nail Samples from Maiduguri Metropolis, Borno State, Nigeria. World Environ. 2012, 2, 81-89. [CrossRef]

15. Hu, C.W.; Wang, C.J.; Chang, L.W.; Chao, M.R. Clinical-scale high-throughput analysis of urinary 8-oxo-7,8-dihydro-2'-deoxyguanosine by isotope-dilution liquid chromatography-tandem mass spectrometry with on-line solid phase extraction. Clin. Chem. 2006, 52, 1381-1388. [CrossRef] [PubMed]

16. Ramos, O.; Carrizales, L.; Yáñez, L.; Mejia, J.; Batres, L.; Ortiz, D.; Diaz-Barriga, F. Arsenic increased lipid peroxidation in rat tissues by a mechanism independent of glutathione levels. Environ. Health Perspect. 1995, 103 (Suppl. 1), 85-88. [PubMed]

17. Ghatak, S.; Biswas, A.; Dhali, G.K.; Chowdhury, A.; Boyer, J.L.; Santra, A. Oxidative stress and hepatic stellate cell activation are key events in arsenic induced liver fibrosis in mice. Toxicol. Appl. Pharmacol. 2011, 251, 59-69. [CrossRef] [PubMed]

18. Singh, B.; Kulawiec, M.; Owens, K.M.; Singh, A.; Singh, K.K. Sustained Early Disruption of Mitochondrial Function Contributes to Arsenic-Induced Prostate Tumorigenesis. Biochemistry (Mosc.) 2016, 81, 1089-1100. [CrossRef]

19. Erhola, M.; Toyokuni, S.; Okada, K.; Tanaka, T.; Hiai, H.; Ochi, H.; Uchida, K.; Osawa, T.; Nieminen, M.M.; Alho, H.; et al. Biomarker evidence of DNA oxidation in lung cancer patients: Association of urinary 8-hydroxy-2'-deoxyguanosine excretion with radiotherapy, chemotherapy, and response to treatment. FEBS Lett. 1997, 409, 287-291. [CrossRef]

20. Toraason, M.; Hayden, C.; Marlow, D.; Rinehart, R.; Mathias, P.; Werren, D.; DeBord, D.G.; Reid, T.M. DNA strand breaks, oxidative damage, and 1-OH pyrene in roofers with coal-tar pitch dust and/or asphalt fume exposure. Int. Arch. Occup. Environ. Health 2001, 74, 396-2404. [CrossRef]

21. Kasai, H.; Crain, P.F.; Kuchino, Y.; Nishimura, S.; Ootsuyama, A.; Tanooka, H. Formation of 8-hydroxyguanine moiety in cellular DNA by agents producing oxygen radicals and evidence for its repair. Carcinogenesis 1986, 7, 849-851. [CrossRef]

22. Kosugi, H.; Enomoto, H.; Ishizuka, Y.; Kikugawa, K. Variations in the level of thiobarbituric acid reactant in health humans under different physiological conditions. Biol. Pharm. Bull. 1994, 17, 1645-1650. [CrossRef] [PubMed] 
23. Hu, C.W.; Pan, C.H.; Huang, Y.L.; Wu, M.T.; Chang, L.W.; Wang, C.J.; Chao, M.R. Effects of arsenic exposure among semiconductor workers: A cautionary note on urinary 8-oxo-7,8-dihydro-2'-deoxyguanosine. Free Radic. Biol. Med. 2006, 40, 1273-1278. [CrossRef] [PubMed]

24. Morton, J.; Leese, E. Arsenic speciation in clinical samples: Urine analysis using fast micro-liquid chromatography ICP-MS. Anal. Bioanal. Chem. 2011, 399, 1781-1788. [CrossRef] [PubMed]

25. Hsueh, Y.M.; Hsu, M.K.; Chiou, H.Y.; Yang, M.H.; Huang, C.C.; Chen, C.J. Urinary arsenic speciation in subjects with or without restriction from seafood dietary intake. Toxicol. Lett. 2002, 133, 83-91. [CrossRef]

26. Pan, C.H.; Chan, C.C.; Wu, K.Y. Effects on Chinese restaurant workers of exposure to cooking oil fumes: A cautionary note on urinary 8-Hydroxy-2'-Deoxyguanosine. Cancer Epidemiol. Biomark. Prev. 2008, 17, 335-3357. [CrossRef]

27. Chao, M.R.; Wang, C.J.; Wu, M.T.; Pan, C.H.; Kuo, C.Y.; Yang, H.J.; Chang, L.W.; Hu, C.-W. Repeated measurements of urinary methylated/oxidative DNA lesions, acute toxicity, and mutagenicity in coke oven workers. Cancer Epidemiol Biomark. Prev. 2008, 17, 3381-3389. [CrossRef]

28. Aposhian, H.V.; Gurzau, E.S.; Le, X.C.; Gurzau, A.; Healy, S.M.; Lu, X.; Ma, M.; Yip, L.; Zakharyan, R.A.; Maiorino, R.M.; et al. Occurrence of monomethylarsonous acid in urine of human exposed to inorganic arsenic. Chem. Res. Toxicol. 2002, 13, 693-697. [CrossRef]

29. Wen, J.; Wen, W.; Li, L.; Liu, H. Methylation capacity of arsenic and skin lesions in smelter plant workers. Environ. Toxicol. Pharmacol. 2012, 34, 624-630. [CrossRef]

30. Vahter, M. Methylation of inorganic arsenic in different mammalian species and population groups. Sci. Prog. 1999, 821, 69-88. [CrossRef]

31. Hsueh, Y.M.; Chiou, H.Y.; Huang, Y.L.; Wu, W.L.; Huang, C.C.; Yang, M.H.; Lue, L.C.; Chen, G.S.; Chen, C.J. Serum $\beta$-carotene level arsenic methylation capability and incidence of skin cancer. Cancer Epidemol. Biomark. Prev. 1997, 6, 589-596.

32. Kumar, A.; Kaundal, R.K.; Iyer, S.; Sharma, S.S. Effects of resveratrol on nerve functions, oxidative stress and DNA fragmentation in experimental diabetic neuropathy. Life Sci. 2007, 80, 1236-1244. [CrossRef] [PubMed]

33. Hu, C.W.; Cooke, M.S.; Tsai, Y.H.; Chao, M.R. 8-Oxo-7,8-dihydroguanine and 8-oxo-7,8-dihydro-2'-deoxyguanosine concentrations in various human body fluids: Implications for their measurement and interpretation. Arch. Toxicol. 2015, 89, 201-210. [CrossRef] [PubMed]

34. Weimann, A.; Belling, D.; Poulsen, H.E. Quantification of 8-oxo-guanine and guanine as the nucleobase, nucleoside and deoxynucleoside forms in human urine by high-performance liquid chromatography-electrospray tandem mass spectrometry. Nucleic Acids Res. 2002, 30, e7. [CrossRef] [PubMed]

35. Takeuchi, T.; Matsugo, S.; Morimoto, K. Mutagenicity of oxidative DNA damage in Chinese hamster V79 cells. Carcinogenesis 1997, 18, 2051-2055. [CrossRef] [PubMed]

36. Langård, S.; Gundersen, N.; Tsalev, D.L.; Gylseth, B. Whole blood chromium level and chromium excretion in the rat after zinc chromate inhalation. Acta Pharmacol. Toxicol. 1978, 42, 142-149. [CrossRef]

37. Li, X.; Pi, J.; Li, B.; Xu, Y.; Jin, Y.; Sun, G. Urinary arsenic speciation and its correlation with 8-OHdG in Chinese residents exposed to arsenic through coal burning. Bull. Environ. Contam. Toxicol. 2008, 81, 406-411. [CrossRef]

38. Fujino, Y.; Guo, X.; Liu, J.; Matthews, I.P.; Shirane, K.; Wu, K.; Kasai, H.; Miyatake, M.; Tanabe, K.; Kusuda, T.; et al. Chronic arsenic exposure and urinary 8-hydroxy-2'-deoxyguanosine in an arsenic-affected area in inner Mongolia, China. Expo. Annal. Environ. Epidemiol. 2005, 15, 147-152. [CrossRef]

(C) 2020 by the authors. Licensee MDPI, Basel, Switzerland. This article is an open access article distributed under the terms and conditions of the Creative Commons Attribution (CC BY) license (http://creativecommons.org/licenses/by/4.0/). 